\title{
Analysis of a dream series by the Dream Coding System developed by Ulrich Moser
}

\author{
Gabriela Pap, ${ }^{1}$ Fritz Lackinger, ${ }^{2}$ Gerhard Kamp, ${ }^{3}$ Henriette Löffler-Stastka ${ }^{4}$ \\ ${ }^{1}$ Sigmund Freud Private University, Vienna; ${ }^{2}$ Vienna Psychoanalytic Academy, Alpen-Adria University, Klagenfurt; ${ }^{3}$ ULG Psychotherapy \\ Research, Postgraduate Unit, Medical University of Vienna; ${ }^{4}$ Department of Psychoanalysis and Psychotherapy, Medical University of \\ Vienna, and Postgraduate Program of Psychotherapy Research, Postgraduate Unit, Teaching Center, Vienna, Austria
}

\begin{abstract}
This paper serves psychotherapeutic process research and shows the process of change in a psychodynamic, individual psychological psychotherapy by means of a theory-based content analysis of the dreams reported in this therapy. The analysis of the patient's dreams is carried out according to the dream coding method by Ulrich Moser and Vera Hortig (2019). The guiding question is about changes in positioning and interactions of the dream elements, how can they be determined and how (within the framework of the underlying dream generation theory) the influence of these changes on the patient's ability to regulate affect can be assessed. Dream coding according to Moser and Hortig uses only the manifest dream and can be regarded as a research tool that rests, among other things, on psychoanalytic concepts, while at the same time taking into account more recent findings in dream and affect research. Its focus is on the coding of the present dream experience and the transformation of dream elements both within individual dreams and in the course of an entire dream series. It allows, without knowledge of the biographical anamnesis and without using psychoanalytic interpretation methods, to recognize changes in the dream structure and the affect regulation produced by it. The coding system thus also offers the possibility of making comparisons regarding the therapeutic changes achieved and thus (at least potentially) the effectiveness of different treatment methods (cf. Leuzinger-Bohleber, 2008, p. $7 \mathrm{f}$.). The coding of several dreams, i.e. the manifest dream content as a dream series highlighted the patient's inner psychic change process: while the safety principle dominated the beginning, involvement increased and the use of the elements was more flexible and the interactions more mixed, to approach the initial dream again towards the end of the dream series. The coding indicates that the patient was able to increase her self-efficacy due to better containment of the emergent (dysfunctional) affects. This coding procedure serves as a promising empirical process assessment for carrying out single case studies.

Correspondence: Henriette Löffler-Stastka, Department of Psychoanalysis and Psychotherapy, Medical University of Vienna, and Postgraduate Program of Psychotherapy Research, Postgraduate
\end{abstract} Unit, Teaching Center, Währinger Gürtel 18-20 A-1090 Vienna, Austria.

Tel.: +43.1.40400.30700

E-mail: henriette.loeffler-stastka@meduniwien.ac.at

Conflict of interests: the authors declare no potential conflict of interests.

Ethical approval and consent to publish: the study was conducted according to the guidelines of the Declaration of Helsinki, the data collected for the study are pseudonymized so that no direct personal reference can be made.

Citation: Pap, G., Lackinger, F., Kamp, G., \& Löffler-Stastka, H. (2021). Analysis of a dream series by the Dream Coding System developed by Ulrich Moser. Research in Psychotherapy: Psychopathology, Process and Outcome, 24(2), 138-155. doi: 10.4081/ripppo.2021.538

Received for publication: 14 March 2021.

Revision received: 22 July 2021.

Accepted for publication: 27 July 2021.

This work is licensed under a Creative Commons Attribution NonCommercial 4.0 License (CC BY-NC 4.0).

${ }^{\circ}$ Copyright: the Author(s), 2021

Licensee PAGEPress, Italy

Research in Psychotherapy:

Psychopathology, Process and Outcome 2021; 24:138-155

doi:10.4081/ripppo.2021.538
Key words: Dream analysis; dream coding method Moser and v. Zeppelin; process analysis.

\section{Introduction}

Dreams and their interpretation are still an essential part of psychodynamic treatments, often they have a central position and become the most important material in the work with patients. For decades, there have also been voices to the effect that dreams and their processing are becoming less important in psychotherapy (Waldhorn, 1967; critically: Greenson, 1970), a tendency that has tended to grow stronger with the questioning of the significance of dreams in the wake of neuroscientific REM sleep research (Crick, 1988; Hobson, 1999). Current efforts to continue to see interpretive work with the dream as an essential and enriching technique of psychotherapeutic practice and to further develop it as such therefore require concepts that allow the dream to be used as an object of research designs, whereby qualitative-quantitative mixed methods are most suitable here (Tillman, Clemence, \& Stevens, 2011). One of the most promising approaches in this re- 
gard is the dream generation theory and dream coding method according to Ulrich Moser, which he first established with Ilka von Zeppelin and later developed further with Vera Hortig (Moser \& v. Zeppelin, 1999; Moser \& Hortig, 2019). This theory combines psychoanalytic dream theory with more recent developments in several neighbouring disciplines and makes it possible to place the dream and its investigation on an objective basis that meets the usual scientific quality criteria (LeuzingerBohleber \& Fischmann, 2017; Döll-Hentschker, 2008; Moser \& v. Zeppelin, 1999).

In the case studied here, however, one of the researchers is at the same time the therapist, i.e. she was directly involved in the therapeutic process. This fact may limit the objectivity of the study. The dream coding method aims to correct this bias, first by strict operative criteria for every code, and secondly by performing the coding through a consensus rating of three raters (including the therapist) trained and experienced in the Moser method.

However, subjectivity as an investigative instrument of the psychodynamic perspective is not to be abandoned. By directing the critical view also towards the quality criteria commonly used in empirical research, an attempt will be made here to alleviate the sharp division between qualitative and quantitative research. The polarization between quantitative and qualitative methods is to be mitigated by using as a basis of quantification sensitively differentiated categories that make use of the subjective perceptiveness of the researchers.

The dream coding system of Moser \& Hortig (2019) meets this requirement. This empirical method targets the manifest dream content and is applied to the dream series that emerged during the patient's treatment. Moser \& Hortig define dreams (and their function) as simulated micro-worlds that represent an attempt to reprocess neurotic conflicts or unresolved traumatic experiences in a simulative form in order to be able to integrate them psychologically (Anstadt, 2016). In this sense, a dream complex is generated into which certain unconscious neurotic or traumatic complex elements enter, and which structurally determines the simulation in the microworld dream. The investigation of the resulting manifest dream content and the changing structures of the dream is done by applying theory-based categories to the dream text (segmentation and coding). The interpretation of the data collected in this way is carried out after coding on the basis of the underlying dream generation theory. The aim here is to trace the change in the unconscious interaction structures and the affect regulation competence of the dreamer based on them (cf. Fischmann \& LeuzingerBohleber, 2017, p. 849 f.). The method is process-oriented and focuses on the narrated dream under the assumption of a consistency bias hypothesis, which states that the dreamed dream is not directly accessible, but despite unavoidable discrepancies with the narrated dream, a far-reaching structural identity can be assumed (cf. Anstadt, 2016).

The coding system does not require psychodynamic or biographical data. Therefore, even researchers and clinicians not trained in depth psychology can use this method to examine, understand, and review the dream and its meaning in the change process of a psychotherapeutic treatment. Beyond the individual case analysis presented in this paper, the coding system also offers the possibility to make comparisons between several treatments (or even treatment methods) in terms of therapeutic processes and internal changes (cf. LeuzingerBohleber \& Moser, 2008).

Finally, there is also the possibility to compare the results of the dream coding method focusing manifest dream content with the perceptions and findings of the clinically involved therapist(s) (cf. Pap, 2017) on affect regulative processes, changes in treatment in order to provide a promising process measurement for empirical psychoanalytic process research and/or single case studies.

\section{Materials and Methods}

Introduction to dream coding according to Moser \& Hortig (2019). The dreams were first written down for evaluation and processed according to the specifications of the manual by Moser \& Hortig (2019). Coding was based on the manifest dream, aiming for the closest possible approximation to the pictorial-sensual experience in the dream (cf. also Döll-Hentschker, 2008). In an initial step called, preparation, the dreams, which are often narrated in the past tense, are reformulated in the present tense; a possible correction of the narrative order may be necessary with the aim of approximating the dreamed dream. Associations and comments added during the telling of the dream are now omitted in order to get as close as possible to the dreamed dream.

According to the manualization in Moser \& Hortig (2019), dream elements are systematically coded according to the parameters position field (PF), motion and trajectories (LTM), interaction field (IAF) verbal relations (VR), and meta-relations (CP/AFF-R).

\section{Position field}

The position field and its elements serve the principle of security, one of the two basic operating principles of psychic life [The other is the involvement principle which is to be coded in the following fields.]. The positionable elements include the subject processor (the dreamer's self), object processors (other persons), inanimate cognitive elements, positional relations and attributes. In the position field we often find latently the highly condensed affectivity of the complex (neurotic or traumatic) experiences that are to be reprocessed. However, the position field is manifestly very low in affect, because the complex-related affectivity 
is not lived out. Affects are caused by interactions, which are not present here. The position field is characterized by spatial relations (cf. Moser, 1992).

\section{Motion and trajectories - loco time motion}

The characteristic feature of loco time motion (LTM) is spatial motion. LTMs do not yet create interactions, because only distance relations are changed. They can be interpreted as approach or avoidance strategies with respect to a problem (cf. Moser, 1992; Moser, 1999; DöllHentschker, 2008).

\section{Interaction field}

Interactions arise in the interaction field. The complex memory structures are activated and potentially reprocessed via interactions. This happens in two phases, the involvement phase and the commitment phase. The involvement phase allows for an increasing affectualization, which, however, remains reversible for a certain time. This is no longer the case in the commitment phase. Interrupts (i.e. breaks in the course of the dream) help to regulate the developing affect. As soon as the affect feels too hot or too cool, changes are made in the position field, or an interrupt follows (cf. Moser \& v. Zeppelin, 1999; Döll-Hentschker, 2009).

With reference to developmental psychological theories, the interactions are divided into different categories, which are of particular importance for the question of involvement, since they indicate the intensity of involvement. Involvement is highest in the self-transformative, response, and resonance relations, whereas displacement relations indicate distancing, whereby affect is down-regulated.

\section{Verbal relations}

Linguistic utterances, whether in the form of individual statements or as a dialogue, represent an abandonment of the immediate sensual-presentational dream level and a use of a more abstract symbolic level. Therefore, they are understood as means of affect control, which, however, do not completely interrupt the sensual dream experience, and sometimes enable a re-polarization, i.e. a re-entering into the sensual process under improved conditions.

\section{Meta-relations}

Unlike the verbal relations, the meta-relations interrupt the sensual-presentational process completely and establish an interrupt. Meta-relations are, on the one hand, explicit cognitive processes (considerations, assumptions, intentions, plans, etc.) that serve to reduce affect and indicate a higher level of control and affect defence (Döll-Hentschker, 2009). On the other hand, explicit expressions of affect also belong to meta-relations, since they are equivalent to a verbal commentary on the dream event, which is thereby interrupted.

\section{Process analysis}

The forms of interaction activated in the dream complex contain conceptions of self and object on the one hand and affective connections on the other. The affects involved, however, have lost their meaningful attachment to concrete persons; Moser calls them unbound affects (Moser 1992), which condemn these interactions to fruitless repetition. In order to be able to speak of a successful attempt at resolution in relation to the (neurotic or traumatic) dream complex, it is absolutely necessary that the conflictual or split-off affective information be transformed back into a relational reality and further developed in it. In this process, there must be an intentional experience of the self and an affective communication with the object. Unbound affectivity must be transformed back into bound affectivity. This is an essential task of dream generation (Moser \& v. Zeppelin, 1999, p. 30).

The processing of dreams in psychodynamic psychotherapies can make the dream-revealed and affectively reoccupied relational patterns even clearer by also connecting them with the transference-countertransference constellation and making them understandable as current relational events. Therapeutic changes will then be reflected in the structure of the subsequently activated dream complexes and enable correspondingly modified forms of interaction. Dream coding can make such changes visible and thus make the unconscious therapeutic process a bit clearer and more comprehensible. In any case, this is the heuristic hypothesis underlying this article. In the course of the therapeutic work investigated here, the patient recounted nine dreams within one year. These are subsequently presented and analysed according to the dream coding method of Ulrich Moser \&Vera Hortig (2019).

\section{Results: dream series}

Editing according to dream coding by U. Moser \& V. Hortig (2019).

\section{First dream}

'I'm at my aunt's house. Mom, dad and aunt are there. I want to pack up my things and leave, everyone is trying to stop me from going away from them. Everyone, even my father, accuses me of being selfish, wants to hold me back. I startle.'

\section{Segmentation dream 1}

S1 I am at my aunt's house. Mom, dad and aunt are there.

S2 I want to pack up my things and go,

S3 everyone is trying to prevent me from walking away from them.

S4 Everyone, even my father, accuses me: You are selfish.

EX AFF R I startle. 
Coding Manual Moser \& Hortig (2019)

S1 I am at my aunt's house. Mom, dad and aunt are there.

SP

$\mathrm{OP}_{1}$ bek (aunt)

$\mathrm{OP}_{2}$ bek (mom)

$\mathrm{OP}_{3}$ bek (dad)

PLACE (house)

ATTR (my aunt)

POS REL INST (CONT)

S2 I want to pack up my things and go,

SP IRC pot

CEU ANON mult (things)

S3 Everyone is trying to prevent me from walking away from them.

SP IRC RESP com hindering (trying to hinder me) $\mathrm{OP}_{4} \mathrm{G}$ (all)

S4 Everyone, even my father, accuses me: You are selfish.

SP $\quad \mathrm{VR} \mathrm{OP}_{3}-\mathrm{SP}((($ You are selfish $)))$ MESS init repud

$\mathrm{OP}_{4}(\mathrm{G})$

$\mathrm{OP}_{3}$ bek (father)

EX AFF R I startle.

EX AFF R WAKE-UP

\section{Evaluation dream 1}

The dream begins with a familiar scene for the dreamer with known reference persons at a familiar PLACE (aunt's house). At first, the initial scene of the dream indicates little movement and dynamism and serves the principle of security. Affects are not explicitly present; instead, an overall effect is felt that can be assigned to this place (Moser \& v. Zeppelin, 1999, p. 52).

While the dynamics are not dramatic, the familiar object processors (aunt, mother, and father) in the position field nevertheless contain information about their potentiality. Moser (1992, p. 930) sees objects (as in children younger than six) (as) an extension of situations or their substitution. Most importantly, an object can also represent an interaction between objects. (author GP translation) In this sense, a cognitive element can assemble diverse information.

The dream organization has chosen a particular PLACE element in this first scene, house of Aunt, linked this to the known object processors Aunt, Mother and Father to activate the unresolved neurotic complex.

The PLACE element is equipped with an attribute. At- tributes indicate that there can be a transition to interactions (Moser \& Hortig, 2016, p. 316). This affective information is inactive, which has the consequence that it is not represented experientially. Only the interactive use in interactions allows the unfolding of affective experiences in the form of affective relations or self-experiences (Moser, 1992, p. 945). In this respect, the positioning field knows only spatial relations and no affects. A richly endowed position field allows high emotional security, and at the same time the possibility of involvement. The flexibility in dealing with the overwhelming affects can be increased by the large number of elements in the position field, this allows always new positionings to try out new approaches.

Object processors have potential on the one hand to be reference figures, generated according to the pattern of the evoked companion (Moser \& v. Zeppelin, 1999, p. 64). In this case, they automatically generate the sensation of being with someone with whom one interacts. In that case, a direct interaction is necessary. On the other hand, object processors can also be a delegation object of self-parts that are unwanted or unavailable (unconscious) to oneself.

Since there is no interaction in the first sequence, these are obviously inner objects, in the form of introjects, which continue to exert their effect on the dreamer's inner world.

The POS REL INST (CONT) also indicates that an introjective microworld is instantiated, i.e., the subject processor (SP) and the object processors (OP) are in a hopeless situation and the defence of the introjectively created relational structure is about to fail. At the same time, SP and OPs are trapped in a container-substitute (house) from which they cannot get out without help (Moser \& Hortig, 2019, p. 115). The potentiality of this first scene is shown in the hope that the object processors will approve of the dreamer's detachment process.

In the next scene, a weak type of interaction is introduced in the form of an IRC pot. Here, the IRC pot is linked to the new element CEU mult (things). This succeeds in changing the microworld and an interaction can take place. IRC pot stands for a potential connexionistic relation, i.e., an anticipation of what can follow without having to experience it scenically.

A slow approach to a more intense interaction is prepared. This is necessary to regulate the affectivity (probably threatening anxiety) connected with the dreamer's intention (to separate). This indicates the modality of affect regulation through the introduction of a potentiality, because in the next scene the familiar OPs enter into a relation with SP in the form of an IRC RESP com hindering, which shows a very high affective relational regulation. An interactional relation that amounts to a response relation indicates a regulation of relationality at a higher level of psychological development (cf. Moser, 1992, p. 946). At this point, affective tension increases, and the dream moves into the commitment phase (Moser \& Hortig, 2019, p. 88). Here, person-processors are resumed, which have their own regulatory modules that (can) be applied in the relationship 
with the subject processor. Two subjective worlds meet, each knowing of the other's inner world, with the intention of finding a common regulation (Moser \& Hortig, 2019, p. 89). The dreamer's wish is not granted. The mood tilts, becomes aggressive and the dreamer can experience that her wish for autonomy is not met. The object processors hold on to her and prevent her intention.

However, the approach to familiar OPs is associated with strong anxiety, which is regulated by a VR MESS init repud, i.e., the dreamer creates affective safety through (emotional) distance. The figurative level is abandoned, thus reducing affective involvement. This shows the increased need of the dreamer for a stronger control over the affective events. It is striking that the OP bek (father) is explicitly mentioned in this scene. The dreamer must experience the father as unhelpful as well. The depressive constellation, which becomes apparent in the stuck situation, remains despite an attempt at a solution.

The dream stops with a startle, i.e., affect regulation fails and the dream complex cannot be completely processed. According to Moser \& v. Zeppelin (1999, p. 142 ), a failure of the dream and thus also the fear maintenance are an indication that affect regulation is attempted but cannot be sustained. This indicates a weak defensive work of the dream in relation to affect actualization. It is an affect that appears in the context of known OPs and a concurrent intention, a desire, of the SP.

Accordingly, the patient's desire for change is clearly visible and can be seen in the fact that she forms interactions between SP and OPs in the following scenes, in the form of IRC RESP and VR relations, respectively. However, the affect cannot lead to an adequate integration, therefore the dream breaks off with the interrupt of the EX AFF R WAKE-UP.

\section{Second dream}

I'm in my hometown and want to take the train to the city where I did my training. It's night, dark, and I don't know my way around the train station. I get on a train; there are many trains at the station. The trains are being moved. From the train I am sitting in, the wagon is uncoupled. Inside is my luggage, something like a military or sailor's bag. I'm desperately looking for the luggage and I can't find it.

\section{Segmentation dream 2}

S1 I am in my hometown

$\mathrm{CP} \quad$ want to take the train to the city where I did my training

S2 It's night, dark, and I don't know my way around the station.

S3 there are many trains at the station. The trains are moved.

S4 From the train in which I am sitting, the wagon is uncoupled. In there is my luggage, something like a military or sailor's bag.
S5 I'm desperately looking for the luggage and I can't find it anymore

\section{Coding}

S1 I am in my hometown

SP

PLACE $_{1}$ prox ATTR (home)

CP Want to take the train to the city where I did my training

\section{CP PROS}

S2 It's night, dark, and I don't know my way around the station.

SP

$$
\begin{array}{r}
\operatorname{PLACE}_{2} \text { (station) } \\
\text { ATTR }_{1} \text { (dark) } \\
\text { ATTR }_{2} \text { (night) }
\end{array}
$$

S3 there are many trains at the station. The trains are moved.

SP IRD NPR ((IRC PHYS)) (moved)

CEU mult (many trains)

$\mathrm{PLACE}_{2}$ (station)

S4 From the train in which I am sitting, the wagon is uncoupled. In there is my luggage, something like a military or sailor's bag.

SP

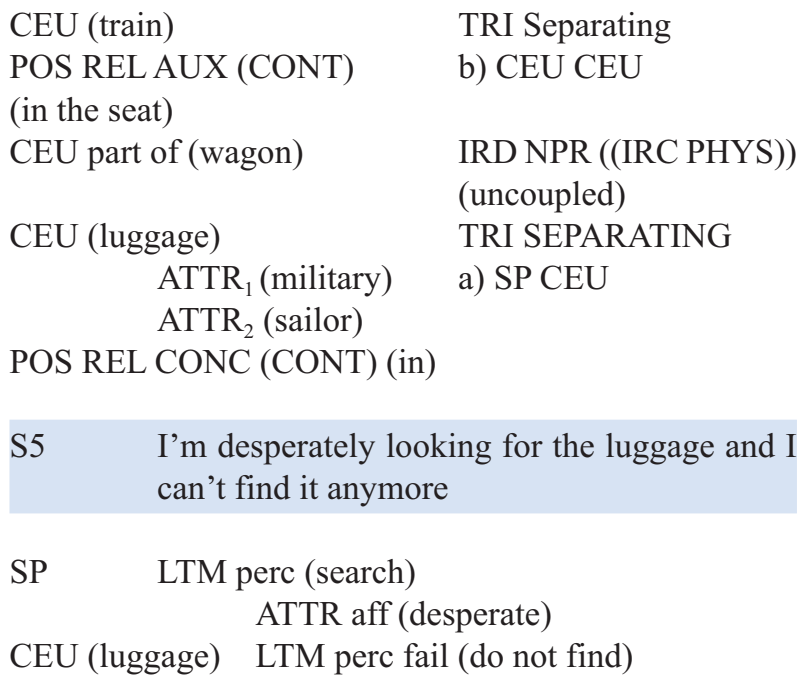

\section{Evaluation dream 2}

The second dream begins again with the patient's location on the basis of a PLACE element. The PLACE el- 
ement of the second dream is chosen differently than in the first dream. A transformation of the PLACE (aunt's house) in a train station of the hometown has taken place in order to incorporate the unresolved complex from the first dream in a newly designed microworld.

In this first scene, the dreamer cannot yet experience herself as involved in the course of events, i.e., stability and security are again of great importance at the beginning of the dream. The patient's self-regulation occurs through the localization and introduction of a $\mathrm{CP}$, which enables a distancing from movement and involvement. Only in the form of a thought can the dreamer's intention, to leave home, make entrance into the dream event.

The task of an involvement is (...) to transform unbound or incorrectly linked affective information into intentionally bound information (Moser \& v. Zeppelin, 1999, p. 76) (author's GP translation). A certain pattern of dream structure can already be seen here: The positional field in the dream is rich in elements that develop their potentiality in the course of the dream. Interactions of high intensity are possible, even if interrupts are repeatedly necessary to regulate the high affectivity.

If one pursues the question of how affective changes become manifest, the Moser-Hortig method reveals prototypical situations. The beginning of the change process is in the position field. In the interaction field, it becomes apparent to what extent the possibilities of the position field can be utilized, i.e., the position field should develop relationally in order to arrive at an affectualization that is tied to feedback processes and affective reactions as well as to attempts to regulate the interaction relations (cf. Moser \& v. Zeppelin, 1999, p. 76). This cannot yet be addressed in the first sequence. First, this newly emerging PLACE requires a cool-down of the associated affects by a CP PROS.

In the second scene the PLACE element is specified and endowed with several attributes. The dreamer tries to approach the threatening affect and looks for the adequate environment for a new attempt to solve it.

The attempted solution is not successful, because an interrupt follows in the form of a CP RETRO. In it, the affect of confusion and fear is wrapped up. Only in the next scene an integration attempt occurs. An IRC KIN becomes possible; thus the subject processor tries to gain control over the introduced CEU (train). The sensorimotor-perceptual encounter with the CEU makes the affective interaction less demanding (Moser \& Hortig, 2019, p 95).

An object can also be hidden in the CEU, perhaps the therapist or a containing in the therapeutic relationship. The train is the supporting partner of the relationship. The situation with the trains is affect-laden. However, the affect is distributed on the PLACE, one can only guess it. The action unfolds as the trains are moved. This is associated with a loss of control, she experiences a loss of her power and self-efficacy. A (violent) dissolution of the introjective micro-world takes place. The trains are moved by an anonymized group, not individ- ualized figures, again suggesting loss of control. The luggage figuralizes a portion of traumatic memory associated with great affectivity.

Here again a transformation of the elements from the first dream is shown. The things that the dreamer cannot pack because she is prevented from doing so by the object processors are transformed to the luggage. Self-parts may be packed in it, which are obstructive, but forcible removal causes great anxiety. The transformation of the object processors into CEUs does allow movement and an attempt at resolution, but it all seems to happen too quickly and there is a threat of loss of control.

The CEU (luggage) is a drop because it falls out of the dream. This indicates a presumed problem that cannot be broken down, but shows up as a perception (cf. Moser \& Hortig, 2016, p. 329).

The fourth scene is characterized by a physical-level interactive relation observed on a secondary interaction field from the subject processor. Several CEUs find their way into this scene. These stand in a relation to each other. Here, the processing of affect succeeds via a physical relation in the secondary interaction field, i.e., commitment is still prevented and affect defence is evident (Moser \& Hortig, 2019, p 97). This indicates a regulation of the relationship at a rather low developmental level (cf. Moser, 1992, p 945). Physical elements are not attributed motivations, affects, self-experiences, beliefs, or desires, therefore the linkage on a physical basis is a more controllable one.

In the next two scenes, a CEU (part of), another CEU with two attributes, and the elements POS RELAUX CONT and POS REL CONT (CONC) are added. These trigger triangular relations that are separative and fearful here.

The POS REL elements indicate the relation of distance, which is presumably a reflection of a social distance (cf. Moser \& v. Zeppelin, 1999, p. 55) that may still prevail in the therapeutic situation.

On the one hand, the element POS REL AUX (CONT) shows a containing in the secondary field, which can be self-parts of the subject processor that are enclosed in a dangerous form. On the other hand, various forms of narcissism are represented by this element, which provide protection from the instatement of the introjective position (Moser \& Hortig, 2019, p. 117). The second POS REL element also indicates introjective constellations of relationship formation. These are present as disruptive signs of a lack of integration (Moser \& Hortig, 2019, p. 121).

In the next scene, at least one movement succeeds in the form of LTM perc. This shows the possibility of changing the position field or at least trying to do so (Moser \& Hortig, 2019, p 81).

The newly introduced CEU (luggage) can be considered as the patient's self-part seeking a new positioning. Thus, the potentiality of this CEU increases. Further involvement in the form of an interaction can no longer take place in this dream.

What remains is a bad feeling. 


\section{Third dream}

I am standing with my mother and aunt in front of the ruins of my maternal great-uncle's house. Mother and aunt look at me expectantly and demand that I do something: I should rebuild the house. But I know that's impossible, because you can't step on the foundation, because then you would immediately collapse, fall in, fall into a hole in the ground.

\section{Segmentation dream 3}

\section{Situation Text}

S1 I am standing with my mother and my aunt in front of the ruins of my maternal great uncle's house.

S2 Mother and aunt look at me expectantly.

S3 They ask me to do something, rebuild the house.

CP But I know it's impossible, because you can't step on the foundation, because then you would immediately collapse, fall in, fall into a hole in the ground.

S1 I am standing with my mother and my aunt in front of the ruins of my maternal great uncle's house.

\section{SP}

$\mathrm{OP}_{1}$ bek (mother)

$\mathrm{OP}_{2}$ bek (aunt)

CEU mult (ruins)

CEU (house)

ATTR (of the great uncle)

$\mathrm{OP}_{3}$ bek ass (great uncle)

ATTR (maternal)

\section{LOC PLACE}

S2

Mother and aunt look at me expectantly.

$\begin{array}{ll}\mathrm{SP} & \text { IRC RESP com } \\ \mathrm{OP}_{1} \text { bek (mother) } & \text { ATTR AFF (expectant) } \\ \mathrm{OP}_{2} \text { bek (aunt) } & \end{array}$

S3 They ask me to do something, rebuild the house.

\section{SP}

$\mathrm{OP}_{1}$ bek (mother)

$\mathrm{OP}_{2}$ bek (aunt)

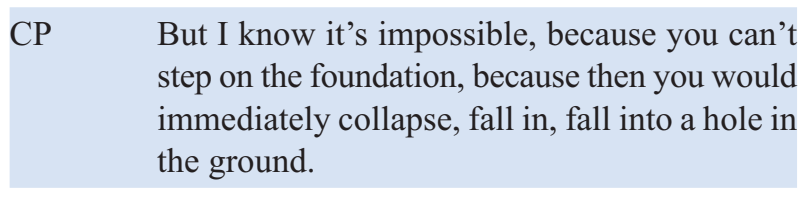

\section{CP INSTEAD}

\section{Evaluation dream 3}

The third dream begins similarly to the first two dreams. Only positioning in the first scene is possible. The dreamer resumes elements from the first dream. The second dream was apparently too boldly constructed and therefore a return to the originally chosen PLACE (house) takes place. Linked to this are the object processors Mother and Aunt. The father was transformed into the element CEU (house) with the ATTR (of the great uncle). This allows some control over an object processor. A CEU has no possibility to influence the affective relationship. The male object must be neutralized, after which interaction with the female object processors can take place.

The dreamer directs his or her attention to the OP bek and is focused on the position field. Attributes indicate the SP's desire for change (cf. Moser \& von Zeppelin, 1999, p. 47).

A response interaction develops in the next scene. The female object processors mother and aunt seem to be overstraining in it.

This experiences a transformation to a verbal relation in the following scene with the same OP bek. With the verbal relation the dream gets stuck, a further development of the dream event is not possible and ends with an interrupt in the form of a CP INSTEAD. A scenic representation on the present tense level has not succeeded, instead it is mentally held that the request of the two known object processors cannot be fulfilled. This type of $\mathrm{CP}$ is characterized by complex reflexivity. It involves not only situations, but also the associated state affect. Moser and Hortig (2019, p. 05) see this as a sign of advanced mentalization of affect. The focus is on internal processes that can prevent further failure here. A distancing to the $\mathrm{OP}$ bek can take place in the $\mathrm{CP}$ and thereby, the already introduced theme of separation and development of autonomy of the first dream complex, be further processed.

Again, the dream breaks off without having solved the dream complex. A separation from the introjective world can only be accomplished in the CP. A present scene is not yet possible. The associated affect is high, but no longer leads to a startling from sleep. This time, the dreamer has set a rehearsal action in the dream, which has given her sufficient control over the dysfunctional affect, which is why the startling does not occur.

\section{Dream 4}

I am in a vacation rental with my current family. It's a big apartment, and we're packing everything up, departure to follow. (...) At the same time, a row of old people with walking sticks suddenly comes and marches past me through the living room. The landlady explains to me that the elevator is broken, and it is easier for the old people if they go up one floor, then they can take the elevator down. I'm a little puzzled, but it's okay with me. (...) We leave the house. We are (...) a little late. My husband reassures me that we don't have to take the kids to school until 10. (...) The husband and the son go by car, me and my daugh- 
ter walk. It's dark outside, it's been snowing, we're having a hard time getting around. We are standing in the bus station of my childhood, and the bus has difficulty entering the station because there is so much snow. (...)

\section{Segmentation dream 4}

Situation Text

S1 I am in a vacation rental with my current family. It is a big apartment, and we are in the process of packing everything.

CP The departure follows. (...)

S2 At the same time a row of old people with walking sticks suddenly comes and marches past me through the living room

S3 The landlady explains to me, The elevator is broken, and it is easier for the old people going up one floor, then they can take the elevator down.

EX AFF R I'm a bit puzzled, but it's okay for me. (...)

S4 We leave the house.

CP We are (...) a little late.

S5 My husband reassures me.

S6 He says, we don't have to take the kids to school until 10 (...)

S7 The man and the son go by car,

S8 me and my daughter walk.

S9 It's dark outside, it's been snowing, we're having a hard time making progress.

S10 We are standing in my childhood bus station and the bus is having a hard time getting into the station,

$\mathrm{CP}$ because there is so much snow. (...)

\section{Coding}

S1 I am in a vacation rental with my current family. It is a big apartment, and we are in the process of packing everything.

\section{SP}

PLACE (apartment) IRC kin int ATTR (vacations)

ATTR (large)

OP (G) bek (family) ATTR (current)

CEU ANON MULT (all)

CP The departure follows. (...)

\section{CP PROS}

S2 At the same time a row of old people with walking sticks suddenly comes and marches past me through the living room
OP (G) ANON type LTM ni OP (G) IRC RES LTM (ALT)

CEU mult (walking sticks)

AUX R MEANS

PLACE part of (living room)

S3 The landlady explains to me, The elevator is broken, and the old people have an easier time going up one floor, then they can take the elevator down.

\section{SP VR (OP-SP) MESS init CP \\ OP (landlord)}

ATTR soc

EX AFF R I'm a bit puzzled, but it's okay for me. (...)

EX AFF R ATTR

S4 We leave the house.

SP

IRC RES LTM

OP $(G)$

PLACE (house)

CP We are (...) a little late.

\section{CP RETRO}

S5 My husband reassures me.

SP IRC RESP com fulfilling (calmed)

$\mathrm{OP}_{2}$ bek (husband)

ATTR (mine)

S6 He says, we don't have to take the kids to school until $10(\ldots)$

SP MESS init pros (OP-SP)

$\mathrm{OP}_{2}$ bek (husband)

S7 The man and the son go by car,

SP IRC RES LTM

$\mathrm{OP}_{2}$ bek (husband)

AUX R MEANS

$\mathrm{OP}_{3}$ bek (son)

CEU (car)

$$
\text { S8 } \quad \text { Me and my daughter walk. }
$$

SP IRC RES LTM

$\mathrm{OP}_{4}$ bek (daughter)

S9 It's dark outside, it's been snowing, we're having a hard time making progress. 
SP

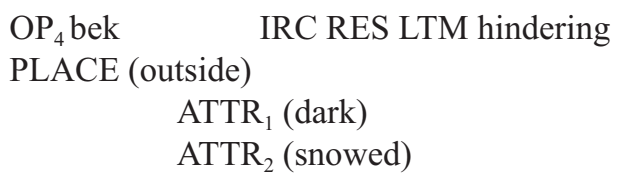
S10
We are standing in the bus station of my childhood and the bus can hardly enter the station

\section{$\mathrm{SP}$}

$\mathrm{OP}_{4}$ bek

PLACE (bus station)

ATTR (of my childhood)

$\begin{array}{ll}\text { SP } & \text { LTM i CEU > } \\ \text { CEU (bus) } & \text { ATTR (hardly) } \\ \text { PLACE (station) } & \end{array}$

$\mathrm{CP}$ Because there is so much snow. (...)

\section{CP RETRO}

\section{Evaluation dream 4}

This dream leads to the present. The dreamer sets a PLACE Element at the beginning of the dream with OPs bek, from the current life situation, some ATTR and connected with two interactions, a resonant one and an IRC KIN. The PLACE element was transformed. The house became a vacation home and the OP bek are updated this time, it is the dreamer's new family. Once again, the dreamer enters an involvement, however this bold movement is interrupted by a cognitive process. The replacement of the dream complex into the current life situation seems to overwhelm the dreamer.

In the next scene a new element appears in the position field, an anonymized group. The anonymization of the former OP bek enables the longed-for farewell, which is prevented in the first dream and accompanied with loss of control and great anxiety in the second dream.

The old people can represent the transformed OP bek of the former dreams. The desired separation can now take place. But the final separation is only possible by implementing it in the Verbal Relation linked to the new OP bek (landlady), who can stand for the therapist.

There must seem to be a change from the pictorial processing, which is the primary way of processing the dream, to a verbal level. This happens when the attention of the SP or OP is to be changed very quickly by the dreamer. It could mean to draw

the attention from unwanted (unconscious) information to socially desired information (cf. Döll-Hentschker, 2008, p 341). Here, this could concern affective information. This process indicates more prominent superego parts (cf. ibid.).
This is followed by an explicit expression of affect. An EX AFF R can be understood as information that the subject processor makes in the form of a self-experience in her intentional field (cf. Moser \& v. Zeppelin, 1999, p. 78). By concretely naming the inner affective state, the dreamer simultaneously distances herself from the affect.

The avoided affect of the last scene is stored, and the interrupted situation as well as the associated affective information are regenerated in the next scene (cf. Moser \& v. Zeppelin, 1999, p. 78). Through the interrupt, three different feedbacks can be experienced: on the one hand, feedback about the dreamer's self-image, about selfagency, and about the affective relationship that has accompanied the interaction. This feedback succeeds only when there is an awareness of affective information. This implies that there is some communicative readiness about affective signals. In fact, an IRC RES LTM is introduced along with OPs letting go. The resonant interactions are seen as weakly developed relationality because they are not so much motivationally or affectively based, but rather serve to maintain the parallelization of behaviour. These are still very close to LTM; further interaction is only implied as a goal, but is not undertaken (Moser \& v. Zeppelin 1999, p. 90 f.).

Immediately after the interaction, however, an interrupt occurs again. A cognitive process is introduced after this scene and means that intentionality is separated from activity and interaction (cf. Moser \& v. Zeppelin, 1999, p. 101). The dreamer has to receive feedback again after this scene about the consequences of the change. The stored affect is taken up and intensified in the next scenes (IRC RESP and VR). IRC RESP shows affective interactions running circularly between two processors. There is a joint affective regulation of the interaction in a dyadic relationship (cf. Moser \& v. Zeppelin, 1999, p. 91 f.). Subsequently, a pole reversal from the sensitive to the auditory channel occurs. This pole reversal can be directed towards something or away from something (cf. Moser \& v. Zeppelin, 1999, p. 104 f.). The dreamer here shifts attention from a burning affect to a reconstructed scene with new elements and processors. The affect can be better sustained and processed in the next scenes. Further IRC RES LTM are possible.

If the OPs and CEUs represent self-parts of the dreamer, these come into movement. This change requires some safeguarding, which is achieved by introducing a new PLACE and separating the OP $(\mathrm{G})$ into two OP groups each, again comprising either only female or male object processors. The male object processors leave the dream, what remains are the female object processors, who have difficulty in accessing the processing of the dream complex.

The dream ends with a cognitive comment. The further affectualization is thus prevented, the temperature of the affects is lowered again. 


\section{Fifth dream}

My brother and I are standing in front of our aunt's house. The aunt is standing a bit apart and is acting quite passively. The house is to be sold, and the buyers are just inspecting the house. Before my eyes, the house is collapsing. It's like a natural disaster, it can't be stopped. In the first moment, I am shocked. (...) But in the second moment I have another thought: the house is not the most valuable thing, the property is. The buyers can be glad that the house collapsed, because they save themselves from demolition. The aunt is quietly watching in the background all the time.

\section{Segmentation dream 5}

Situation Text

S1 My brother and I are standing in front of the aunt's house. The aunt stands a little apart and behaves quite passively. The house is to be sold.

S2 The buyers are currently inspecting the house.

S3 The house collapses before my eyes.

CP It's like a natural disaster. It is unstoppable

EX AFF R At the first moment I am startled. (...)

$\mathrm{CP} \quad$ But in the second moment I have another thought:

The house is not the most valuable thing, the property is. Buyers can be glad that the house collapsed, because they save demolition.

S4 The aunt watches silently in the background all the time.

\section{Coding}

S1 My brother and I are standing in front of the aunt's house. The aunt stands a little apart and behaves quite passively.

SP

$\mathrm{OP}_{1}$ bek (brother)

PLACE (house)

LOC PLACE

ATTR (of the aunt)

$\mathrm{OP}_{2}$ bek (aunt)

ATTR (quite passively)

LOC PACE (stands apart)

IMPLW

S2 The buyers are currently inspecting the house.

SP

OP $(\mathrm{G})$

CEU (house) IRD NPR ((IRC RES PERC))

S3 The house collapses before my eyes.

SP

\author{
LOC PLACE (in front of my eyes) \\ IRD NDR ((IRS glob id)) (CEU))
}

CEU (house)

CP It's like a natural disaster, It can't be stopped.

CP RETRO

EX AFF R At the first moment I am startled. (...)

EX AFF R ATTR SP

$\mathrm{CP}$

But in the second moment I have another thought:

\section{CP RETRO}

S4 The aunt watches silently in the background all the time.

SP IRD NDR ((IRC PERC OP))

$\mathrm{OP}_{2}$ bek (aunt)

ATTR (silent)

LOC PLACE (in the background)

\section{Evaluation dream 5}

In this fifth dream, the patient's dream structure is built up on the basis of the CEU and PLACE (aunt's house) already known from the earlier dreams. Again, a scene emerges which seems to be necessary as a preparation for involvement. Before anything can be set in motion, the element IMPLW replaces the task that presents itself and cannot yet be set in scene with a mere announcement. The task again indicates a violent, uncontrolled separation.

The subject processor and the object processor are fixed in the scene by the localization in the element LOC PLACE. The object processor aunt must be additionally fixed again by an attribute (quite passively), because the next scene is about change, which leads to a parting (from the aunt's house).

A change of scene occurs, new OPs and an IRS, a selfchange of a CEU, in the secondary field, are brought in.

IRS are relations that reflect changes in self-regulation. (Moser \& Hortig, 2019, p. 84) (author's GP translation). Self-change is shifted to a secondary field and it happens uncontrolled. The self-stabilization module is disrupted, and the self-reorganization module seeks processes to reshape the subject processor. IRS relations witness attempts at restoration (Moser \& Hortig, 2019, p. 85 ). The dreamer allows the old house to collapse and only the property remains, which is perceived as very valuable. The difficulty of leaving the old introjective world behind is clearly shown by this IRS and becomes even clearer by the following EX AFF R.

This third sequence shows the fear of loss of control, 
which is transferred to the CEUs (house) collapsing, an irreversible change that can be represented by the CEU but apply to the SP or OPs. This sequence is followed by three cognitive processes and one explicitly stated affect. This indicates that the dreamer is trying to keep the actualized affect under control, to cool it down enough, to tolerate it, in order to initiate a new attempt at resolution. This succeeds in the last scene. The dreamer finds the solution by reintroducing an OP bek, namely the aunt, into the scene to provide emotional security.

The dream leads back into the past, this is shown by the known PLACE element and the object processor aunt. At the same time, a new OP bek (brother) is introduced, but this object processor is not mentioned right after the first scene. It is a drop after the self-change. With the new object processor (brother) affects are updated that are linked to the activated dream complex. This linkage still seems too overwhelming, so the new OP is dropped in the next scenes.

\section{Sixth dream}

I'm at the aunt's house. There are quite a lot of people. I have to make room for all the people to sleep. There are family members from my mother's side of the family. My aunt is also there and has her place in her bed. A second cousin is there with two children who are parentless. One child, a girl, is about four years old, and one baby, a little boy. It is a challenge to find a place for all of them, but after several attempts to find the right place for each, I have the solution, so finally all of them can lie well and fall asleep. The parentless girl finds a place quite quickly and can fall asleep quickly and well. I feel an incredibly great love towards the parentless baby. I find a very special place for this baby. The place is soft and warm and safe, so the baby cannot fall out of bed.

When the solution is found, my father arrives. At first it feels like too much to find a place for him, too. But I try it, give a fauteuil to the side, but that doesn't fit, I don't want the father to sleep on the bare floor. So, I get a blanket out of a cupboard that my aunt has knitted, put it on the floor in the kitchen and thus also create a good place for my father. The spot isn't as ideal because he's not in the same room as everyone else, but it's soft, right by the connecting door between the room and the kitchen. This feels like a good enough solution. I'm relaxed, I've done the job well.'

\section{Segmentation dream 6}

Situation Text

S1 I am at the aunt's house. There are a lot of people there. They are family members from my mother's side of the family.

$\mathrm{CP}$ I have to make room for all the people to sleep.

S2 My aunt is also there and has her place in her bed. A second cousin is there with two children who are parentless. One child, a girl, is about four years old, and one baby, a little boy.

$\mathrm{CP} \quad$ It is a challenge to find a place for everyone so that finally everyone can lie well and fall asleep. after several attempts, I have the solution.

S3 The parentless girl finds a place quite quickly

S4 and can fall asleep quickly and well.

EX AFF R I feel an incredible love towards the parentless baby.

S5 For this baby I find a very special place. The place is soft and warm and safe,

CP so that the baby cannot fall out of bed.

S6 When I find the solution, my father comes.

EX AFF R At first, it feels like too much to find a place for him, too.

S7 But I am trying.

S8 I give a fauteuil to the side, but it does not fit.

CP I do not want the father to sleep on the bare floor.

S9 Therefore, I get a blanket out of a closet that my aunt knitted,

S10 put them on the floor in the kitchen and also create a good place for my father.

$\mathrm{CP} \quad$ The space is not so optimal because it is not in the same room as everyone else,

S11 but it is soft, just by the connecting door between the room and the kitchen.

EX AFF R That feels like a good enough solution. I am relaxed, I have done the task well.

S1 I am at the aunt's house. There are a lot of people there. They are family members from my mother's side of the family.

SP

PLACE (house)

ATTR (of the aunt)

OP (G)

ATTR (family members)

ATTR (maternal) $\mathrm{CP}$ I have to make room for all the people to
sleep.

\section{CP PROS}

S2 My aunt is also there and has her place in her bed. A second cousin is there with two children who are parentless. One child, a girl, is about four years old, and one baby, a little boy.

SP

$\mathrm{OP}_{1}$ bek (aunt)

CEU (bed)

POS REL INST (CONT) 


$\mathrm{OP}_{2}$ bek (cousin)
ATTR (second)
$\mathrm{OP}_{2}$ ANON type (child)
ATTR (parentless)
ATTR (girls)
ATTR ( 4 years)
$\mathrm{OP}_{3}$ ANON type (baby)
ATTR (parentless)
ATTR (little boy)
$\mathrm{CP} \quad$ It is a challenge for everyone to find a place so
that finally everyone can lie well and fall asleep.
after several attempts, I have the solution.

\section{CP PROS}

S3 The parentless girl finds a place quite quickly

SP

$\mathrm{OP}_{2}$ ANON type (girl) IRD NDR ((IRC KIN int OP)) ATTR (parentless)

ATTR (fast)

\section{CE (Place)}

S4 And can fall asleep quickly and well.

SP

$\mathrm{OP}_{2}$ ANON type $\quad$ IRD NDR ((IRS OP)) (fall asleep)

\section{ATTR (fast)}

ATTR (good)

EX AFF R I feel an incredible love towards the parentless baby.

\section{EX AFF R ATTR}

S5

For this baby I find a very special place. The place is soft and warm and safe,

SP IRC (find)

$\mathrm{OP}_{3}$ ANON type (Baby)

CE (Place)

ATTR (special)

CE add (place)

ATTR (soft)

ATTR (warm)

ATTR (safe)

\section{CP}

PROS So that the baby cannot fall out of bed.

S6 When I find the solution, my father comes.

SP

LTM OP (come)

IRC (find)
$\mathrm{CE}$ (solution)

$\mathrm{OP}_{4}$ bek (father)

EX AFF R At first, it feels like too much to find a place for him, too.

\section{EX AFF R}

S7

But I am trying.

SP

IRC (trying)

S8

I give a fauteuil to the side, but it does not fit.

SP

IRC KIN int (give) fail

CEU (fauteuil)

LOC PLACE (to the side)

$\mathrm{CP}$ I do not want the father to sleep on the bare floor.

\section{CP PROS}

S9

That's why I'm getting a blanket out of a closet that my aunt knitted,

SP

CEU (blanket)

IRC KIN int (getting)

ATTR (from my aunt)

ATTR (knitted)

CEU (closet)

POS REL CONC (CONT)

S10 put them on the floor in the kitchen and also create a good place for my father.

\section{SP}

IRC KIN int (put)

CEU (them)

PLACE (kitchen) IRC (create)

part of (floor)

LOC PLACE

CE (place)

$\mathrm{OP}_{4}$ bek (father)

ATTR (good)

CP The space is not so optimal because it is not in the same room as everyone else,

\section{CP RETRO}

S11 He lies soft, just by the connecting door between the room and the kitchen.
SP

$\mathrm{OP}_{4}$ bek (father)

IRD ((IRS OP)) (lies)

CEU (door)
ATTR (soft)
ATTR (connection) 


\section{SUB PLACE (room) \\ SUB PLACE (kitchen) \\ POS REL INST (CONT)}

EX AFF R That feels like a good enough solution. I am relaxed, I have done the task well.

\section{EX AFF R}

\section{Evaluation dream 6}

First, the dreamer sets herself and the PLACE element from the first dream. This time, however, unknown OPs are introduced, which then gradually become OP known on the basis of ATTR. In contrast to the development from the first dream, which ends abruptly by an EX AFF R (WAKE UP), this time the involvement can be maintained, albeit by the introduction of CPs and explicit mention of unpleasant affects. The dream is characterized by many cognitive processes; thus, the dreamer succeeds in continuing the dream. She repeatedly transforms the scenes in order to advance the complex processing.

Before the next scene an interrupt is introduced, then OP bek (aunt) is inserted into the scene, which is provided with attributes that explicitly name a flat affectivity, but without an interaction relation, i.e., a certain caution is necessary for the dreamer. A POS REL INST (CONT) is set, which again points to the already known introjective world, which she wants to transform here.

Finally, from the 3rd sequence on, interactions between SP and OPs occur, which enable a change. The dreamer can perceive in the interaction the self-transformation of the OPs, which she has intentionally initiated. This continues in the next sequence. However, the dreamer seems to be approaching an intense affect, a cooling of involvement is necessary. This happens at first by a CP PROS to succeed.

The SP introduces a self-configuration here, the girl who is described unpretentiously. However, the parentless girl' seems to trigger a high affectivity, which leads to an interaction, but this is only observed in the secondary field, from a distance.

The turning to the OP (baby) needs the introduction of an interrupt, an EX AFF R, which explicitly names the affect of love. This love is for the baby (her brother), but since the baby could also be a self-part, the love would be understood as self-love.

This explicitly mentions the dreamer's ability to positively engage in intimate relationships or to allow a very positive access to certain parts of herself. The dream continues by increasing the involvement again through an IRC, which denotes interrelationships, but in a less intense and differentiated form.

The dream focuses on a new OR in the next scene, the father is introduced and immediately requires cooling down in the form of thoughts or an explicitly named affect (the overload). The male gender here again requires a lot of care.
Fittingly, this care is easy to provide towards a baby, whereas towards the father it becomes difficult. Therefore, at first the interaction is connected with a fail. A new cognitive process in the form of an explanation follows.

The dreamer now shifts into motion and introduces an LTM element, along with a host of other elements that seem necessary to actualize and rebind the overwhelming affect associated with the OP bek (father).

The introduction of many elements from the positional field indicates that the affect overwhelms the dreamer, which is why security elements are needed, which gradually find their way into the scene and are connected to the OP bek (aunt). The approach of the OP bek (father) is apparently still fearful. It succeeds an IRC KIN. The assumption is that dream complexes from early disturbances can only be experienced in these IRC KIN and thus are not yet accessible in a reorganized linkage of two person micro-worlds (cf. Moser \& Hortig, 2016, p. 317). The affects associated with the father still seem to be experienced only with great caution, whereas the OP bek (aunt) is no longer associated with anxiety and overwhelm. Despite fear, the representation of the conflictual theme is successful, which speaks for the fact that the dreamer was able to develop a greater tolerance for fear.

\section{Seventh dream}

During the session, the patient remembers a dream she had the week before. Her mother appears in it:

I was sick and got a shot at the doctor's office. After that, I felt really good for the first time. The medicine before that didn't help. The next day the effect was gone. I would have liked to get another one from the doctor, but there were so many people. I got the shot and wanted my mom to help me, to have my mom give me the shot. But my mother said in the dream that she couldn't, even though she was a nurse. In the dream I had the feeling: That's how it is, my mother can't help me, I resigned myself to that.

It was one of the few dreams where I am alone with my mother. I feel no anger, no disappointment, no sadness. I've come to terms with it.

\section{Segmentation dream 7}

Situation Text

S1 I am sick and get an injection at the doctor's office.

EX AFF R After that, I feel really good for the first time.

CP The medicine before that did not help. The next day the effect is gone

S2 I would like to get a new one from the doctor, but there are so many people.

S3 I get the injection

CP and would like my mother to help me, to give me the injection.

S4 But my mother says, I can't do it, CP although she is a nurse.

EX AFF R I feel like this: my mother can't help me. 
Coding

S1 I am sick and get a injection at the doctor's office.

SP

$$
\text { ATTR (sick) }
$$

SOC SET (at the doctor)

CEU (injection)

$\mathrm{OP}_{1}$ (doctor)

EX AFF R After that, I feel really good for the first time.

\section{EX AFF R}

CP The medicine before that did not help. The
next day the effect is gone.

CP RETRO

CP I would like to get a new one from the doctor,

CP PROS

S2 But there are so many people.

SP

OP (G) ANON (many people)

S3 I get the injection

SP IRC KIN c

CEU (injection)

CP And would like my mother to help me, to give me the injection.

\section{CP Pros}

S4 But my mother says, I can’t do it,

SP MESS init IRC miss (OP - SP)

$\mathrm{OP}_{2}$ bek (mother)

CP Although she is a nurse.

\section{CP RETRO}

EX AFF R I feel like this: my mother can't help me.

\section{EX AFF R ATTR}

\section{Evaluation dream 7}

This dream has a different beginning than the dreams before. The dreamer does not set an introduction in the form of a positioning, there is an interaction as IRC RESP bod between SP and a new OP (doctor). The positional field is reduced to a narrower field of relational figures with the SOC SET element, here it is evident that the dreamer focuses on the therapeutic relationship and questions it in the transference. An OP bek (mother) from the earlier dreams is mentioned in the form of a verbal relation. The problematic affect cannot allow interaction, therefore this affect is actualized anew in the safe (emotional) distance.

An abortion of the dream is not necessary here, as it happened in the first dream, the affect tolerance has increased and the dreamer has other possibilities to regulate the affect, to try out solution approaches. The affects are explicitly mentioned, and at the same time a distancing from them takes place, which is achieved by the verbal relation or comments and explanations.

The CEU (injection) from the first scene is resumed in the next sequence. This can be a very difficult to decode representation of a dream complex. Once this is linked to an interaction, an affective experience may be possible. But a distancing is necessary again, the present experience cannot be maintained further, the turning to the OP bek (mother) can only be represented in the form of a thought.

These changes indicate a better affective processing of the problematic or traumatic experiences. An IRC KIN can trigger an affect in the counterpart (therapist), i.e. the affective information could enter the therapeutic relationship in the form of countertransference feelings. The active communication of affects is not possible in the IRC KIN; this only happens in the IRC RES or IRC RESP (cf. Moser \& Hortig, 2016, p. 322).

\section{Eighth dream}

I'm at the aunt's house. Father explains to me (or maybe grandfather) that he put an ingenious heating system in the house, with shafts in the walls, so that the warm air from the chimney can spread everywhere. He did that because I used to freeze like that when I was a kid (as did my little brother).

The next scene is in the kitchen in Aunt's house: the kitchen is flooded with water. The water is murky. Father says he carved a little ship when I was little and shows it to me. The little ship looks a little like a chess piece. And now this little ship is still in very good condition. I can try it out - I can push the little ship down, knock it over I'll see the little ship doesn't sink.

\section{Segmentation dream 8}

Situation Text

S1 I'm at the aunt's house.

S2 Father explains to me, I put an ingenious heating system in the house, with shafts in the walls, so that the warm air from the chimney can spread everywhere.

CP He did that because I used to freeze like that when I was a kid (as did my little brother). 
I'm in the kitchen at Auntie's house. The kitchen is flooded with water. The water is murky.

S4 The father says: I carved a little ship when you were little.

S5 He shows it to me. The little ship looks a little like a chess piece. And now this little ship is still in very good condition.

S6 I can try it out - I can push the little ship down, knock it over - I'll see, the little ship won't sink.

S1 I'm at the aunt's house.

SP

PLACE (house)

ATTR (of the aunt)

$\mathrm{OP}_{1}$ bek ass (aunt)

S2 Father explains to me, I put a sophisticated heating system in the house, with ducts in the walls, so the warm air from the fireplace can spread everywhere.

SP

$\mathrm{OP}_{2}$ bek (father)

$\mathrm{CP} \quad \mathrm{He}$ did that because I used to freeze like that when I was a kid (as did my little brother).

\section{CP RETRO}

S3

I'm in the kitchen at Auntie's house. The kitchen is flooded with water. The water is murky.

SP

SUBPLACE (kitchen)

ATTR (flooded)

PLACE (house)

ATTR (of the aunt)

$\mathrm{OP}_{1}$ bek ass (aunt)

CE stuff (water)

ATTR (murky)

S4 The father says: I carved a little ship when you were little.

SP

VR $(\mathrm{OP}>\mathrm{SP})(((\mathrm{IRC} \mathrm{KIN})))$

$\mathrm{OP}_{2}$ bek (father)

S5 He shows it to me. The little ship looks a little like a chess piece. And now this little ship is still in very good condition.

IRC RESP perc
$\mathrm{OP}_{2}$ bek (father)

CEU (shuttle)

ATTR (like a chess piece)

ATTR (in good condition)

S6 I can try it out - I can push the little ship down, knock it over - I'll see, the little ship won't sink.

SP

VR MESS int (OP> SP) (((IRC KIN, IRC PHYS)))

$\mathrm{OP}_{2}$ bek (father)

\section{Evaluation dream 8}

Again the dream begins with the usual introduction, the PLACE from the earlier dreams. The other OP bek (mother, father) seem to have entered the PLACE, a deanimating transformation that offers more control over the affective events. The enactment allows the patient's sense of safety to increase. But at the same time, her desire for involvement also increases, because the atmosphere associated with this PLACE, explicitly named by the attribute, allows for the reactivation of problematic affects.

The atmosphere from the fifth dream, in which an affective situation could not be solved well enough, is brought up again here and a new approach to a solution is sought. The problematic affects are tied to the OP bek (father), which is why this finds its way into the second scene, albeit from the safe distance of the verbal relation, in that the father is presented as caring and nurturing.

This is followed by the third sequence, which leads to a new positioning. A new SUBPLACE is sought and a CEU stuff with attribute is also set as an element in the position field, which suggests an increased need for security on the part of the dreamer, as well as the fact that the dreamer is focusing her attention on the changes that are about to take place. But first follows another verbal relation, again tied to the OP bek (father). Interactions with the father can be experienced in this dream only after repeated attempts and repositioning. Finally, an IRC RESP perc occurs between SP and OP with a CEU with attributes and ends in the last sequence again with a verbal relation in which a request from the father to the daughter is packaged. Again, the interaction is reduced, i.e., the affectualization is too high; the dreamer does not find another attempt to regulate affect in this dream.

\section{Ninth dream}

I am in the weekend house of my family of origin, where I spent a lot of time in my childhood. I am looking at the house and garden from a corner of the garden. In the house is my father. Everything is quite neat there. Not only in the house, but also in the garden everything is orderly. The garden is full of flower beds, all looking very neat and tidy, full of small plants that are thriving. New neighbours have moved in vis-à-vis. It is a young couple, and they come to introduce themselves. (...) I am quite re- 
assured, there is someone who is always here to keep an eye on my father(...).

\section{Segmentation dream 9}

Situation Text

S1 I am in the weekend house of my family of origin, where I spent a lot of time in my childhood.

S2 I look at the house and garden from a corner of the garden.

S3 In the house is my father. Everything is quite orderly there. Not only in the house, but also in the garden everything is orderly. The garden is full of flower beds, all looking very neat and tidy, full of little plants that are thriving.

S4 New neighbours have moved in vis-à-vis. It is a young couple, and they come to introduce themselves. (...)

EX AFF R (...) I am quite reassured,

$\mathrm{CP}$ there is someone who is always here and can keep an eye on my father. (...)

\section{Coding}

S1 I am in the weekend house of my family of origin,

where I spent a lot of time in my childhood.

SP

PLACE (house)

ATTR (weekend)

ATTR (my family)

IMPLW

S2 I look at the house and garden from a corner of the garden.

SP

IRC PERC (look)

CEU (house)

CEU (garden)

LOC PLACE (from a corner)

S3 In the house is my father. Everything is quite orderly there. Not only in the house, but also in the garden everything is orderly. The garden is full of flower beds, all looking very neat and tidy, full of small plants that are thriving.

SP

OP bek (father)

CEU (house)

ATTR (neat)

POS REL INST (CONT)

CEU (Garden)

ATTR (ordered)

CEU add (garden)
CE MULT (beds)

ATTR (tidy)

ATTR (neat)

PFL mult

ATTR (small)

ATTR (thrive)

POS REL CONC CONT (full with)

S4 New neighbours have moved in vis-à-vis. It is a young couple, and they come to introduce themselves. (...)

SP

$\mathrm{OP}(\mathrm{P})$

IRD NDR ((IRC RES LTM OP))

LOC PLACE

IMPLW (moved in vis-à-vis)

EX AFF R (...) I am quite reassured,

EX AFF R ATTR

$\mathrm{CP}$ There is someone who is always here and can keep an eye on my father. (...)

\section{CP PROS}

\section{Evaluation dream 9}

The initial scene now contains a PLACE element that has not yet appeared in the previous dreams. The structure of the first scene is similar to that of the initial dream. The OPs were not set explicitly, these find entrance into the first scene by the attributes.

The dreamer repositions herself in a in the second sequence, thus changing the distance relations and introducing the element PFL for the first time in a dream. Plants are static and lack the possibility of movement. Thus, they can only be used in a limited way for the causal causation of interactions (cf. Moser \& v. Zeppelin, 1999, p. 66). The dreamer introduces an element from the positional field, which probably offers a lot of security by its static existence, nevertheless it allows change, especially self-change. However, the change that can come from plants is far more controllable than change that comes from OPs or animals. This kind of design of the second sequence may be an indication of the dreamer's need for security, which she is now able to give herself through her increased affect tolerance and changes in object representation. The dreamer succeeds better and better in acting intentionally in such a way that she can regulate her relationships and the associated affects to such an extent that she no longer has to fear an affect overflow. Although she apparently again brings forth an affect that has not yet been processed well enough and that is connected to the OP bek (father), she is able to keep the affectualization at a level that makes it possible for her to process the dys- 
functional affect to some extent. There is no interaction in the third scene when the OP bek (father) is introduced. The patient further secures herself with several elements in the position field, which are endowed with attributes. The position field along with its associated attributes contains affective information. Instead, POS REL appear again in various forms, as in the first dreams. In these, introjective micro-worlds are captured in different ways, changes are thus prevented. The dream process threatens to come to a standstill, as a situation of being trapped in a hopeless situation is instated (Moser \& Hortig, 2019, p 115 ff).

In the next scene, new OPs are introduced and an interaction occurs in the IRC Resp mode and in the form of an IRC RES in the secondary interaction field. According to this, the relationship regulation happens in displacement according to the resonance principle, (...) in which affects are used to trigger processes in the partner that proceed from a change in the joint relationship regulation (...) (Moser \& v. Zeppelin, 1999, p. 42). However, the dream ends with a cognitive process and an explicitly stated affect. The conflict does not yet come to rest completely with the solution found in the dream, the affective distancing is finally not accepted as a suitable solution.

\section{Discussion: analysis of the coding of the dream series}

With the coding system according to the Moser and Hortig method, an analysis of the dream events can be performed on the basis of the manifest dream. Changes that occur from scene to scene in individual dreams, but also from dream to dream, can be traced. The changes in dream structure and affectualization are thus traced.

It should be noted, however, that statements about changes and transformations in a dream series are only possible to a limited extent insofar as it must be about dreams which deal with the same complex. In this dream series it is clearly evident that the dreamer repeatedly activates a complex which is linked to early objects (aunt, mother, father, brother). This is partially transferred to the present by focusing on the current affective relationships with the current family members or therapist.

The process of transference is visible in the current therapeutic relationship already in the second dream. The PLACE element of the first dream (aunt's house), which is repeatedly set, changes into a new PLACE (train station/hometown). Not the figures and relations are transformed in this case, but their features (Moser \& Hortig, 2019, p. 131).

The OPs of the first dream are fixed by deanimation. The affective quality is now distributed over the positional field. A loss of control threatens the dreamer. According to this, the dreamer is groping in the dark at a station where many things are in motion without being able to keep control over them. This can be an indication of the beginning psychotherapeutic treatment.

The first dream contains only a few elements and situations. Similar in the structure of the dream is the third dream. Both dreams have identical PLACE elements and OPs. The change in the structure of the two dreams is shown to a small extent by the intensity of the interactions and interrupts. Involvement increases in the third dream, affect regulation succeeds a bit better, startling out of the dream is no longer necessary.

The dreamer equips the position field more and more richly in the next dreams. This indicates a potentiality that the dreamer is still developing in the course of the therapy. In fact, the number of situations, the elements as a whole, but especially the interactions and at the same time the cognitive processes grow until the sixth dream. After that, the number of situations and elements decrease and the dreams resemble the structure of the initial ones. This shows that the patient can increase her involvement in the course of the therapy, leave the positional field and exploit the potentiality of the positional field more and more in the course of the therapy process. Therefore, new affective experiences are allowed, which make it possible to work on the dysfunctional affects or the inner relational models.

What is striking is the dominance of the relationship with the early caregivers, first and foremost the aunt. This relationship could be subjected to changes, just like the relationship to the father. However, the mother conflict remains, without the possibility of a new evaluation and positioning. This may show a deeper (early) disturbance. This assumption is strengthened by recurrent POS REL elements, which indicate introjective worlds and are probably traces of early disturbed object relations.

\section{Conclusions}

In summary, it can be said that the safety principle dominates at the beginning. Afterwards, the involvement increases to approach the initial dreams again towards the end of the dream series (Figure 1).

The elements introduced are very similar, what has changed is the more flexible use of the elements. These do not always require more interactions, but they are more mixed, which in turn indicates that the patient was able to increase her self-efficacy due to better containment of the emergent (dysfunctional) affects.

\section{References}

Anstadt, T. (2016). Das Traumgenerierungsmodell von Ulrich Moser und die Codierung von Traumprozessen. Forum der Psychoanalyse, 32, 245-266.

Crick, F. (1988). Neural networks and REM sleep. Biosci Rep., $8,531-535$.

Döll-Hentschker, S. (2008). Die Veränderung von Träumen in 


\section{DREAM ELEMENTS}

70

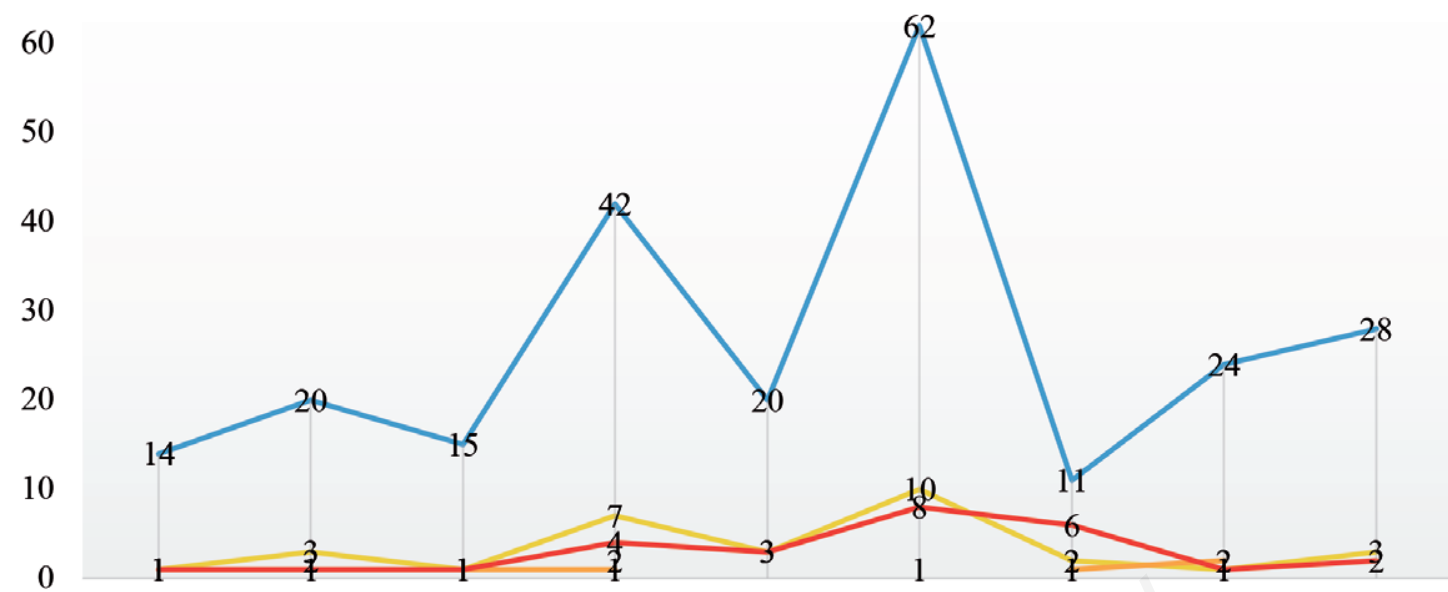

1st dream 2nd dream 3rd dream 4th dream 5 th dream 6 th dream 7 th dream 8 th dream 9th dream

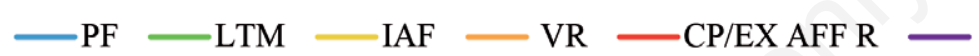

Figure 1. Dream elements. PF, position field; LTM, motion and trajectories; IAF, interaction field; VR, verbal relations; CP/AFFR: meta-relations.

psychoanalytischen Behandlungen. Affekttheorie, Affektregulierung und Traumkodierung. Frankfurt an Main: Brandes \& Apsel Verlag.

Döll-Hentschker, S. (2009). Die Veränderung von Träumen im Laufe einer analytischen Behandlung. Psychoanalyse - Texte zur Sozialforschung, 13(2), 188-199.

Fischmann, T., Leuzinger-Bohleber, M. (2017). Veränderungen von Träumen als Indikatoren für Therapieerfolg. Teil 2: Theoriegeleitete Inhaltsanalyse von manifesten Trauminhalten im Schlaflabor. Trauma - Zeitschrift für Psychotraumatologie und ihre Anwendungen, 15(2), 80-89.

Greenson, R. R. (1970). Die Sonderstellung des Traums in der psychoanalytischen Therapie. In Greenson, R. (Ed.), Psychoanalytische Erkundungen (pp. 336-363). Stuttgart: Klett-Cotta (1978).

Hobson, A. J. (1999). The new neuropsychology of sleep: implications for psychoanalysis. Neuropsychoanalysis, 1, 157-183.

Leuzinger-Bohleber, M., Fischmann, T. (2017). Veränderungen von Träumen als Indikatoren für Therapieerfolg. Teil 1: Manifeste Trauminhalte von traumatisierten Patienten in Psychoanalysen. Trauma - Zeitschrift für Psychotraumatologie und ihre Anwendungen, 15(2), 70-79.

Leuzinger-Bohleber, M., Moser, U. (2008). Vorwort. In DöllHentschker, S. (Ed.), Die Veränderung von Träumen in psychoanalytischen Behandlungen. Affekttheorie, Affektregulierung und Traumkodierung (p. 10). Frankfurt am Main: Brandes \& Apsel (2008).

Moser, U. (1992). Zeichen der Veränderung im affektiven Kontext von Traum und psychoanalytischer Situation. Psyche.
Zeitschrift für Psychoanalyse und ihre Anwendung, 11, 923958.

Moser, U., von Zeppelin, I. (1999). Der geträumte Traum - Traumgenerierung und Traumcodierung. In Deserno, H. ( $2^{\text {nd }}$ edition), Das Jahrhundert der Traumdeutung (pp. 375-398). Stuttgart: Kohlhammer-Verlag.

Moser, U. (1999). Das Traumgenerierungsmodell (Moser, von Zeppelin) dargestellt an einem Beispiel. In Bareuther, H., Brede, K., Ebert-Saleh, M., Grünber, K. Haus, S. (Eds.). Traum, Affekt und Selbst (pp. 49-82). Tübingen: Edition diskord.

Moser, U. (2013). Was ist eine Mikrowelt? Psyche. Zeitschrift für Psychoanalyse und ihre Anwendung, 67, 401-431.

Moser, U., Hortig, V. (2014). Interaktive Relationen im Traum. Psyche. Zeitschrift für Psychoanalyse und ihre Anwendung, 68, 336-362.

Moser, U., Hortig, V. (2016). Deanimierte Objekte im Schlaftraum. Psyche. Zeitschrift für Psychoanalyse und ihre Anwendung, 70, 314-336.

Pap, G. (2017). Überlegungen zur individualpsychologischen Traumdeutung heute. Forum der Psychoanalyse, 33,319336.

Tillman, J. G., Clemence, J. A., Stevens, J. L. (2011). Mixed Methods Research Design for Pragmatic Psychoanalytic Studies. Journal of American Psychoanalysis Association, 59(5), 1023-1040.

Waldhorn, H. F. (1967). Indications for psychoanalysis. The place of the dream in clinical psychoanalysis. New York, NY: International Universities Press. 